\title{
O SISTEMA ELEITORAL PROPORCIONAL E O MULTIPARTIDARISMO NA FORMAÇÃO DO PRESIDENCIALISMO BRASILEIRO DE COALIZÃO
}

\author{
The proportional electoral system and the multipartism in the formation of the \\ brazilian coalitional presidentialism
}

\author{
Luiz Henrique Borges de Azevedo Silva
}

Nayra Juliana Daniel de Azevedo

Resumo: $O$ artigo promove uma análise sobre os sistemas eleitorais brasileiros na escolha de governantes e representantes. O sistema adotado pela Constituição Federal de 1988 criou um modelo político que acabou se autoconsumindo pela própria forma de organização. Porém, ao prever que a escolha dos representantes do Poder Legislativo far-se-ia através do sistema proporcional porque este seria um modelo ideal de preservar as ideologias partidárias e permitir maior representatividade ideológica no Poder Legislativo, não contava que o excessivo número de partidos poderia esfacelar o próprio sistema em que fora instituído. Deste modo, vê-se que a deturpação do sistema proporcional acaba por conflitar com a sustentação do presidencialismo brasileiro. O objetivo do presente trabalho é apresentar como a mistura de um sistema eleitoral proporcional nos moldes existentes no Brasil somada ao multipartidarismo é capaz de destruir o presidencialismo brasileiro.

Palavras-chave: Sistemas eleitorais. Multipartidarismo. Presidencialismo de coalizão.

\begin{abstract}
The article promotes an analysis of the Brazilian electoral systems in the choice of leaders and representatives. The model adopted by the Federal Constitution of 1988 created a political model that ended up consuming self by the form of organization. To provide that the choice of the representatives of the legislature would be under the proportional system because this would be an ideal model to preserve partisan ideologies and allow greater ideological representation in the legislature lacked the partisan excess could shatter the system that was instituted. Thus, the distortion of the proportional system ultimately conflict with the support of Brazilian presidentialism. The aim of this paper is to present as a mixture of a proportional electoral system in existing molds in Brazil coupled with the multi-party system is capable of destroying the Brazilian presidentialism. Keywords: Electoral systems. Multipartism. Coalitional presidentialism.
\end{abstract}

Artigo recebido em 27 jul. 2017 e aprovado em 13 nov. 2018. 


\section{Introdução}

Os sistemas partidários são formas de escolha para se chegar aos representantes do povo, visto que atualmente a democracia pura, com a participação popular direta, não é medida possível. Esses sistemas são formas de escolha, podendo, segundo as fundamentações de suas criações, refletir a voz do povo através de uma pessoa (sistema majoritário) ou de ideologias (sistema poroporcional).

No Brasil, o sistema majoritário foi o escolhido para as eleições do Poder Executivo, entre elas, para a do Presidente da República. Ocorre que, no sistema presidencialista, embora haja a previsão constitucional da separação e independência dos poderes, vê-se que, na verdade, essa independência não funciona exatamente como se imaginava, vez que há uma estreita ligação entre Executivo e Legislativo na tomada de decisões do país.

Para as eleições do Poder Legislativo, a Constituição de 1988 achou por bem que a escolha fosse feita através do sistema eleitoral proporcional. Assim, as casas legislativas iriam possuir uma representatividade ideológica maior, permitindo grandes debates para a solução dos problemas do país, coadunando-se com a garantia do pluripartidarismo constitucional, chamado por alguns de multipartidarismo.

Todavia não foi isso que ocorreu, e o multipartidarismo acabou ocasionando um presidencialismo de coalizão dentro da república brasileira, com as relações entre os poderes Executivo e Legislativo tomando caminhos moralmente questionáveis em nome da governabilidade.

Deste modo, este artigo demonstrará o quanto prejudicial o sistema eleitoral proporcional nos moldes escolhidos é para o presidencialismo brasileiro. A forma apresentada pela Constituição de 1988 acabou oportunizando a sua autodestruição ao mesclar um multipartidarismo, sem bases ideológicas, com os fortes laços entre os poderes Executivo e Legislativo para buscar a governabilidade do país.

\section{Sistema majoritário para as eleições do executivo}

Os sistemas eleitorais visam à organização das eleições e à conversão de votos em mandatos políticos, buscando proporcionar uma captação eficiente, segura e imparcial da vontade popular demonstrada de maneira democrática, de modo que os mandatos eletivos sejam exercidos com legi- 
timidade. Ainda cabe aos sistemas eleitorais prover meios para que os diversos grupos sociais sejam representados e as relações entre representantes e representados se fortaleçam (TORRES, 2016).

O sistema eleitoral brasileiro é formado por vários sistemas eleitorais que são usados no país, cuja função é a escolha de seus governantes e representantes. O referido sistema foi criado pela Constituição de 1988 e pelo Código Eleitoral perante a Lei no 4.737 de 1965, sendo também regulada pelo Tribunal Superior Eleitoral (TSE) (XEREZ, 2012).

A Constituição vigente inaugurou em seu texto dois sistemas de representação eleitoral: o majoritário e o proporcional de lista aberta. No primeiro, vence o candidato que obtiver a maioria dos votos, sendo que tal sistema é utilizado nas eleições para os chefes do Poder Executivo e os senadores. Ele se classifica em puro ou simples e em dois turnos ou absoluto. No puro, vence o candidato que obtiver a maioria dos votos. Já em eleição em dois turnos, vence o candidato com a maioria absoluta dos votos válidos (SOARES, 2003, p. 1-24).

O sistema majoritário simples é adotado nas eleições para Senador e Prefeito de Municípios com menos de 200 mil eleitores (art. 29, II, CR/1988). E o sistema majoritário absoluto é adotado nas eleições para Presidente da República, Governadores e Prefeitos de Municípios com mais de 200 mil eleitores (GOMES, 2015).

Dentro do sistema majoritário, é necessário estabelecer o contingente mínimo de votos para que um determinado candidato venha a ser declarado eleito, pois, ao se considerar o sistema de maioria simples, não existe a certeza de que o candidato mais votado tenha recebido mais de $50 \%$ dos votos, e essa situação somente será garantida se for realizado o sistema de dois turnos ou pelo voto alternativo.

\section{O funcionamento do sistema presidencialista}

As relações entre as funções executiva e legislativa dos Estados costumam ser regidas de maneira diversificada conforme o sistema de governo adotado, que pode ser o presidencialista ou o parlamentarista (DANTAS, 2011). Segundo Soares (2003, p. 4):

As características originárias do presidencialismo são encontradas na formação desse sistema de governo, nos Estados Unidos da América. Os colonos não tinham e não queriam os nobres e a monarquia. 
No entanto, eles criaram um novo Estado e precisavam de um mecanismo eficiente para governar, diferente dos tradicionais, existentes no Velho Mundo. Nesse ambiente nasceu o presidencialismo, um sistema de governo marcado pelo equilíbrio entre os Poderes Legislativo e Executivo. Nele, o líder maior não recebe o cargo por herança, mas também não pode ser retirado dele conforme as tempestades políticas; o Legislativo cria as leis, mas o Executivo pode impedir o nascimento de leis impróprias para o país; o governo é unipessoal, marcado pela predominância do Executivo, o qual depende, no entanto, do Legislativo para conduzir as decisões do Estado. Tudo isto registrado em uma Constituição, Lei Maior, capaz de manter as regras dessa estrutura e dar segurança à sociedade.

No Brasil, o sistema político é presidencialista, constituído por três poderes: o Executivo, o Legislativo e o Judiciário, os quais são exercidos, respectivamente, pelo presidente da República, pelo Parlamento (no caso do Brasil, Câmara dos Deputados e Senado Federal) e pelo Supremo Tribunal Federal, a Corte Suprema (LEITE, 2016).

Para auxiliar o Presidente da República, foram criados os Ministros de Estado, pessoas de sua confiança que podem, a qualquer momento, ser nomeados e, também, exonerados, sendo que a produção das leis fica a cargo do Congresso Nacional. Dentro desse sistema, a principal característica é a independência dos poderes. Desse modo, a mudança de presidente não significa a mudança na força dos partidos no congresso, e vice-versa (LEITE, 2016).

Dantas (2011, n.p.) e alguns doutrinadores contemporâneos descrevem um terceiro sistema de governo, o qual é chamado de semipresidencialismo, em que existem duas figuras.

O primeiro, a do chefe de governo (em muitos casos, com a denominação de primeiro-ministro), que exerce o poder executivo, mas não na sua totalidade; o segundo, a do chefe de estado, denominado de Presidente, que dirige a política externa, e também exerce uma parcela de funções executivas.

Nessa perspectiva, o Poder Executivo, ao incluir a direção da Administração Pública, atua, de maneira compartilhada, de algum modo, por dois titulares. 
De acordo com Leite (2016), o sistema presidencialista reconheceu, de forma clássica, o princípio da separação dos poderes. Nesse sistema, o presidente eleito se situa, de maneira direta ou indireta, em relação à origem, em situação de igualdade com o Congresso Nacional. Desse modo, todo o Poder Executivo se concentra na pessoa do Presidente da República, que é Chefe de Estado, Chefe de governo e Chefe da Administração Pública. Devido a essa última característica, costuma-se dizer que, enquanto nos Estados parlamentares os partidos têm história, nos Estados presidencialistas, a história conta-se pela pessoa do Presidente (LIMONGI, 2006).

O modo de operar do governo brasileiro é o mesmo da maioria das demais democracias contemporâneas (VANIN, 2012). O Executivo controla a agenda legislativa, logrando aprovar a maioria de suas proposições, uma vez que está ancorado por sólido e consistente apoio partidário (VANIN, 2012).

Outra característica reside na possibilidade de o partido presidencial não ser majoritário no Legislativo. Um exemplo emblemático foi o do Presidente Collor, eleito pelo Partido da Reconstrução Nacional (PRN), à época, com presença inexpressiva no Congresso Nacional, algo nunca visto na história política do país (LEITE, 2016).

O presidencialismo direciona à compreensão de outras características relacionadas a esse sistema, conforme será exposto a seguir.

\section{O sistema eleitoral proporcional e o multipartidarismo}

O sistema proporcional é um modelo considerado recente, uma vez que somente foi aceito no século XX, embora esteja presente na Constituição Francesa de 1793, tendo sido utilizado pela primeira vez na Bélgica em 1900 (ARAÚJO; NUNES JÚNIOR, 2003).

A principal característica do sistema proporcional é o quociente eleitoral. Tal mecanismo determina os partidos e/ou coligações que ocuparão as vagas em disputa nos cargos de deputados federal e estadual, e de vereador. Esse quociente eleitoral é verificado ao ser dividido o número de votos válidos apurados pelo de vagas a preencher em cada circunscrição eleitoral. Nesse caso, os votos válidos contados são apenas aqueles dados a candidatos regularmente inscritos e às legendas partidárias (Lei no 9.504/1997, art. 5ㅇ․ Para Moraes (2002, p. 985): 
O sistema proporcional adota duas formas para definir quais candidatos serão eleitos: o escrutínio de lista (aberta e fechada) e o voto de legenda. No sistema aberto não há ordem de precedência entre os candidatos apresentados pelo partido, sendo eleitos os que forem mais votados, enquanto na lista fechada o partido confecciona uma lista partidária e estabelece uma ordem de prioridade entre os seus candidatos, em decorrência disso são eleitos os candidatos que estiverem colocados nas primeiras posições da referida lista.

A Constituição Federal de 1988 assegura que esse sistema é utilizado para fazer a composição do Poder Legislativo, com exceção do Senado Federal, que é regido pelo sistema majoritário. Nesse sentido, as vagas de deputados federais, estaduais, distritais e vereadores serão distribuídas em proporção aos votos obtidos pelos partidos ou coligações partidárias.

Para que a distribuição seja proporcional ao número de cadeiras, o distrito deve eleger um número mais ou menos elevado de representantes, havendo a necessidade de ser geograficamente extenso e mais ou menos populoso. Nesse caso, o eleitor votará não no candidato somente, ou no sistema majoritário, mas, num certo número, numa lista de candidatos. $\mathrm{O}$ voto será plurinominal e, por isso, recebe a denominação de "escrutínio de lista”, muitas vezes inapropriadamente (TEIXEIRA, 1991).

A eleição proporcional é usada no Brasil para determinar os representantes da Câmara dos Deputados, das Assembleias Legislativas e das Câmaras de Vereadores. O sistema eleitoral do país prevê a adoção de um sistema de lista aberta, na qual se reúnem os votos gerais dos candidatos de cada partido. Tal ranking dá origem às listas partidárias, compostas pelos candidatos mais votados de determinado partido naquele pleito. Nos sistemas desse tipo, cada partido obtém um número de vagas proporcionais à soma dos votos em todos os seus candidatos, e essas vagas são distribuídas, pela ordem, aos candidatos mais votados daquele partido.

Torres (2016) menciona que, ao contrário do sistema majoritário, o proporcional pode ser realizado de duas maneiras: lista aberta ou lista fechada. No primeiro caso, os eleitores escolhem diretamente seus candidatos. Já no segundo, o eleitor vota somente no partido político, ficando este encarregado de selecionar, por uma votação de lista, os candidatos que verdadeiramente ocuparão os mandatos eletivos. 
No sistema eleitoral proporcional, tem importância o número de votos válidos para o partido político, pois, ao votar na legenda, faz-se a escolha por partido. O art. 109 do Código Eleitoral (Lei no 4.737/1965) esclarece como se chega ao número de votos válidos.

Ao analisar a realidade brasileira, Ramayana (2011) comenta que boa parte da doutrina compreende que o sistema majoritário é mais adequado que o proporcional, uma vez que ele termina por conferir poder aos candidatos que não representam opiniões, já que são eleitos por grupos singularizados. Porém existe uma corrente doutrinária que reconhece que o sistema proporcional é mais apropriado para o exercício democrático do poder, em razão de assegurar às minorias o direito de representação.

O multipartidarismo se caracteriza pela existência de três ou mais partidos, no qual todos têm capacidade de chegar ao poder.

Para Reis (2015), conhece-se por "multipartidarismo" a exagerada proliferação de agremiações partidárias ou, ainda, o sistema pluripartidarista em excesso, a utilização desenfreada do princípio do pluripartidarismo presente no art. 17 da Constituição Federal.

O sistema multipartidário tem cunho bastante democrático ao conferir autenticidade ao governo, reconhecido como centro de coordenação ou compromisso dos distintos interesses presentes nas várias classes da sociedade, classes cuja voz de participação, através do partido político se alça assim à esfera do poder (GOMES, 2015).

Existem atualmente no Brasil 35 partidos políticos em funcionamento e devidamente registrados no Tribunal Superior Eleitoral, e ainda por volta de 30 associações com pedido de registro de legenda em trâmite no TSE. Desse modo, corre-se o risco de o país contar, nos próximos anos, com algo em torno de 60 legendas (REIS, 2015).

De acordo com Crespo (2010), a existência de inúmeros partidos no Brasil não implica que todos têm a capacidade de assumir o poder. A título de exemplo, citam-se os quatro partidos dominantes: PSDB, DEM, PT e PMDB. Contudo, o título "partido dominante" não faz inferir diferença de programas ou ideologias. Basta atentar para as políticas econômicas que são mantidas e as propostas são basicamente idênticas nos conteúdos centrais (educação, saúde, economia).

Por outro lado, no sistema presidencialista, a pulverização partidária é indicada como elemento que enfraquece o regime, ao lhe determinar 
muitas vezes seu colapso. Em sistemas parlamentaristas, o multipartidarismo pode conduzir a governos coalizados, com gabinetes de composição heterogênea, sem rumos políticos coerentes, sujeitos a uma instabilidade inequívoca (CORDEIRO, 2009).

\section{O presidencialismo de coalizão}

Quem primeiro mencionou o termo presidencialismo de coalizão foi Sérgio Abranches (1988). Posteriormente, as reflexões do autor serviram de suporte para outros estudos. Em seu trabalho, Abranches procurou apresentar boa parte dos problemas e complexidades que estariam presentes no sistema de governo presente no Brasil, associando à sua análise política importantes aspectos sociológicos, históricos e econômicos, específicos do caso brasileiro (SANTOS, 2003).

Timothy Power (apud COSTA, 2013) tratou do assunto no texto "O presidencialismo de coalizão na visão dos parlamentares brasileiros" e, nesse artigo, o pesquisador recorreu a vários autores para demonstrar que o presidencialismo de coalizão não é, de maneira nenhuma, uma exclusividade brasileira, pois governos de coalizão existem em $78 \%$ dos países parlamentaristas e em $66 \%$ das nações presidencialistas.

Coalizão diz respeito a acordos entre partidos e a alianças entre forças políticas para alcançar certos objetivos. Em realidades nas quais predomina o sistema multipartidário, no qual há mais que dois partidos relevantes disputando eleições e ocupando cadeiras no Congresso, dificilmente o partido do presidente possuirá ampla maioria no Parlamento para aprovar seus projetos e implementar suas políticas (CODATO; COSTA, 2006).

De acordo com Abranches (1988), a multiplicação de demandas acentua a tendência histórica de intervenção ampliada do Estado, o qual se desdobra em inúmeras agências que desenvolvem diversos programas ao beneficiar distintas clientelas. Espalham-se os incentivos e os subsídios, criam-se a rede de proteção e as regulações estatais. Tal movimento se configura em um resultado aparentemente contraditório, que limita progressivamente a capacidade de ação governamental.

Conforme Ricci (2008):

Uma coalizão é uma aliança de governo (e não apenas eleitoral), típica do parlamentarismo. Ocorre que esta possibilidade foi aberta com a Constituição Federal de 1988, que aumentou sobremaneira o 
poder do parlamento sobre o executivo. $\mathrm{Na}$ época, acreditava-se que o parlamentarismo seria aprovado pelo plebiscito nacional, o que de fato não ocorreu. Assim, criamos uma ambivalência no sistema político que é centralizado como todo presidencialismo, mas vinculado e dependente do parlamento, como ocorre no parlamentarismo. A situação ficou ainda mais complexa na medida em que as bancadas estaduais (nas Assembleias Legislativas e Câmara Federal) ficaram, desde a última eleição, mais vinculadas ao poder de mando dos governadores. Levantamento realizado pelo Instituto Cultiva revelou que 13 governadores atuais comandam diretamente entre 50\% e $75 \%$ das bancadas de seus Estados.

Como se pode depreender, a coalizão acaba por retirar do governo sua independência para governar, pois este fica sempre submetido a alguma aliança ou partido. Nesta perspectiva, sinaliza-se que querer aplicar regras de organização observadas em outras formações sociais, com história e estruturas diversas, corresponderia a um exercício de engenharia institucional artificial e exótico.

Figueiredo e Limongi avaliaram que o resultado da manutenção dessas instituições conduziria a um sistema com fortes tendências à inoperância com risco à paralisia, sendo, portanto, um sistema político em que um presidente impotente e fraco contrapor-se-ia a um legislativo povoado por uma miríade de partidos carentes de disciplina (ABRANCHES, 1988).

Conforme Limongi (2006, p. 20):

Do ponto de vista descritivo, o sistema político brasileiro, não há dúvidas, pode ser nomeado como um presidencialismo de coalizão. Afinal, a forma de governo adotada é o presidencialismo e governos recorrem à formação de coalizões para obter apoio para suas iniciativas. Logo, em si mesmas, essas características não implicam ou justificam a aspiração à originalidade. Mais do que isso, se recorrermos a evidências empíricas sistemáticas, como procurarei mostrar, não é possível manter quer a aspiração à originalidade, quer os juízos negativos. Ainda que trate apenas tangencialmente dos demais pontos, não é possível sustentar que os partidos brasileiros não são capazes de estruturar coalizões partidárias ou que o poder tradicional regule e controle os resultados eleitorais. 
Nesse entendimento, do ponto de vista da sua estrutura, da forma como efetivamente funciona, são poucos os aspectos que distinguem o sistema político brasileiro de outras democracias ditas avançadas ou consolidadas. Isso porque a maneira como o processo decisório é organizado, mais particularmente o poder de agenda conferido ao Executivo, garante ao governo brasileiro a capacidade de operar em bases similares às de grande parte das democracias existentes.

Ricci (2008), ao trazer o tema para a atualidade, cita um exemplo do governo Lula para ilustrar os efeitos nefastos desse sistema.

Consolidado no campo institucional e na base social do país, o governo Lula conseguiu forjar uma poderosa estrutura de poder (e não apenas governo, como chegou a afirmar Frei Betto). Desmantelou qualquer estrutura de participação direta no governo, eliminou as audiências públicas para discutir o Plano Plurianual (PPA) da nova gestão, comunica-se pontualmente com movimentos sociais, não encaminhou a lei de fomento às ONGs, nem abriu os dados de execução orçamentária (o que foi feito pelo Senado através do Siga Brasil) para a sociedade civil. Trata-se de um governo de centro, social-liberal, um mosaico ou condomínio ideológico-partidário. Daí encontrarmos algumas instâncias governamentais mais ou menos próximas aos movimentos sociais, às redes de defesa de direitos sociais, a projetos históricos de organizações populares do país. Seu vínculo e legitimidade com alguns movimentos sociais ocorrem através de transferência de recursos orçamentários ou acordos pontuais.

Nessa perspectiva, a coalizão presidencialista se constitui como um imenso plano de poder e/ou de manutenção do poder político, o qual se articula pelas políticas de transferência de renda e por meio de negociações com as outras forças sociais, sempre pelas vias políticas institucionalizadas, que envolvem todo tipo de representantes públicos e bancadas parlamentares num processo de negociação de cargos e orçamento público.

Ao criticar tal sistema, Piva (2010, p. 32) ressalta que este tende a se transformar da seguinte maneira:

a) Sistema partidário fragmentado, que ameaçaria a governabilidade e a estabilidade do regime democrático;

b) Ausência de partidos fortes, isto é, disciplinados, coesos, programáticos e, por essa razão, aptos a estruturar as preferências políticas dos eleitores; 
c) Falta de vínculos entre os parlamentares e seus eleitores;

d) Proliferação de políticos individualistas que, quando se aproximam de seus eleitores, cultivam uma relação clientelista, oferecendo bens e serviços em troca de votos;

e) Corrupção estimulada pelas regras de financiamento de campanhas.

Analisando-se as colocações do autor supracitado, nota-se que a realidade política do país já sinaliza cada um desses problemas.

Acerca disso, ressalta-se que, quanto menor a dependência eleitoral dos candidatos com relação às respectivas lideranças partidárias, menor também serão a disciplina e a coesão desses partidos em sua atuação parlamentar. Ou, ao contrário, quanto maior for o peso da reputação pessoal do candidato em sua própria eleição e menor a influência do fator partidário, maior deverá ser o paroquialismo expresso no comportamento congressual desse futuro legislador (SANTOS, 2003).

Abranches (1988) complementa ao dizer que muitas análises do caso brasileiro e, sobretudo, a imagem que é passada para a opinião pública do país é que seus problemas emergem de um sistema político frágil. Para o autor, fica evidente que os dilemas do país derivam muito mais da incapacidade das elites em compatibilizar o formato institucional do país com o perfil heterogêneo, plural, diferenciado e desigual da ordem social brasileira.

A partir da fixação do conceito do presidencialismo de coalizão, alguns teóricos brasileiros buscaram compreender as relações entre Executivo e Legislativo, assim como as características de funcionamento com base em coalizões políticas para, tendo por base esse eixo, caracterizar o sistema de presidencialismo pátrio. Entre essas características, estaria uma tipificação particular diferenciada: a de, utilizando-se alguns instrumentos constitucionais, regimentais e de construções de maiorias, sobrepor-se o Poder Executivo ao Poder Legislativo e, aquele sobre este, impor sua agenda política, cabendo ao Legislativo, tão somente, agregar-se ao projeto político vitorioso (MENDES, 2009).

\section{As relações entre o poder executivo e o poder legislativo}

A Constituição Federal de 1988 inaugurou a república presidencialista como forma de governo ao estabelecer como um de seus princípios fundamentais a divisão das funções estatais em três distintos órgãos: o Poder Legislativo, a ser exercido pelo Congresso Nacional; o Poder Executivo, 
a cargo da Presidência da República, e o Poder Judiciário, atribuído aos tribunais e aos magistrados federais e estaduais, variando a competência de cada juízo conforme o determinado em lei.

Em seu art. 49, a Carta Magna confere poder ao Legislativo para interferir nas ações do Poder Executivo.

É de competência exclusiva do Congresso autorizar o Presidente e o Vice-Presidente da República a se ausentarem do País, quando a ausência exceder a quinze dias (inc. III); sustar os atos do Poder Executivo que exorbitem do poder regulamentar ou dos limites da delegação legislativa (inc. V); aprovar iniciativas do Poder Executivo referentes a atividades nucleares (inc. XIX). Ou ainda no art. 50, caput: A câmara dos Deputados e o Senado Federal, ou qualquer de suas comissões poderão convocar Ministro do Estado ou quaisquer titulares de órgãos diretamente subordinados à Presidência da República para prestarem, pessoalmente, informações sobre assunto previamente determinado, importando em crime de responsabilidade a ausência sem justificação adequada. Estes exemplos poderiam ser multiplicados como na competência da Câmara dos Deputados para instauração de processo de contra o Presidente e o Vice-Presidente da República e os Ministros do Estado (art. 51, inc. I).

Com essa disposição, a Carta Magna prevê a interferência de um poder sobre o outro sempre que se fizer necessário. A harmonia no exercício dos Poderes estatais se constitui de respeito mútuo às prerrogativas atribuídas a cada Poder, com colaboração e controle recíprocos, no sentido de construir os objetivos da república. Os Poderes se relacionam de forma tal que há interferências previstas e necessárias ao estabelecimento de um equilíbrio entre eles, na busca de evitar todas as formas de desmando possíveis (MORAES, 2001).

Deste modo, a análise sistemática da dinâmica institucional brasileira, à luz da Constituição de 1988, encontrou na formulação das políticas públicas fonte alternativa de explicação a respeito da interação Executivo-Legislativo. Anteriormente, a ausência de pesquisas sistemáticas sobre os poderes Executivo e Legislativo e o relacionamento entre eles deu azo a alguns juízos negativos e predições catastróficas acerca do comportamento parlamentar e partidário e o papel do Congresso no sistema decisório nacional. 
Há um Estado em que o soberano concentra em si todas as funções: a função de legislar, a de julgar e a de administrar, detendo o controle de tudo e de todos, não cabendo indagações quanto à legitimidade, à qualidade ou mesmo à validade das decisões desse soberano (MORAES, 2001).

Atualmente, não há como negar que o Estado não pode funcionar sem o mecanismo de delegação de poderes. O Parlamento, qualquer que seja sua esfera (Federal, Estadual, Distrital ou Municipal), é um poder lento por natureza. E não pode ser muito diferente (VAZ, 2000).

A relação mais próxima entre os poderes se dá porque o Estado brasileiro abandonou o presidencialismo clássico, com poderes divididos. A evolução da sociedade obrigou uma aproximação, e mesmo uma interferência dos poderes, em especial, do Poder Executivo com o Poder Legislativo.

O Executivo brasileiro organiza o apoio à sua agenda legislativa em bases partidárias, em modelos similares aos regimes parlamentaristas. $\mathrm{O}$ Presidente da República distribui as pastas ministeriais com o objetivo de obter o apoio da maioria dos legisladores; partidos que recebem pastas são membros do governo e devem comportar-se como tal no Congresso, votando a favor das iniciativas patrocinadas pelo Executivo (AVRITZER, 2016).

\section{Mudanças e novas perspectivas}

A realidade do sistema político brasileiro demonstra que reflexões são necessárias para que se construa e/ou reconstrua um modelo que, de fato, tenha sua representatividade frente à população (HAKIM, 2016). Déficit de cidadania é traço marcante da democracia brasileira. Raros são os momentos em que o povo vai às ruas para revelar sua vontade. Desde 2014, porém, nota-se o inconformismo da população por meio de manifestações populares, demonstrando a intolerância com a ingerência e com a corrupção no país (AVRITZER, 2016).

O que se vê é que o presidencialismo de coalizão, de certa maneira, contribuiu para que ocorresse um enriquecimento do poder supremo do país, pois têm-se nesse modelo muitas interferências e, até mesmo, falta de autonomia tanto dos partidos quanto do próprio Poder Executivo (HAKIM, 2016).

Ao analisar o panorama político marcado por fortes crises com a transição de um governo interino para sua formalização após o processo de impeachment da presidente então reeleita por voto popular (1‥1.2015: 
posse $2^{\circ}$ mandato; 1․8.2016: impeachment) é preciso considerar a análise dos representantes do Centro de Referência do Interesse Público (AVRITZER, 2016, n.p.).

Na nossa opinião, o Brasil foi constituído a partir de uma fraca noção de identidade pública e sob a batuta de interesses privados muito fortes. O nosso estado é um estado forte demais para conceder favores e fraco demais para estabelecer com clareza os limites entre o público e o privado, especialmente para os poderosos. É verdade que a opinião pública se indigna com razão a cada um dos episódios políticos, mas a verdade é que a sua raiz reside em aspectos quase estruturais da cultura brasileira. Uma incapacidade de construir uma noção forte daquilo que é público na política.

Essa crítica reside em tudo a que se assiste, pois, a propósito do que já foi citado, o País conta hoje com um número muito grande de partidos que, de um modo ou de outro, acabam se multiplicando e interferindo ao mesmo tempo nas decisões maiores, como as do Poder Legislativo.

A população brasileira aumentou a sua atenção e a sua rejeição à questão da corrupção nos últimos anos. No entanto, têm faltado à população os meios para melhorar a qualidade do sistema político brasileiro. Estes podem vir ou através de iniciativas da sociedade civil ou através de mudanças na legislação e aprimoramentos institucionais que impliquem em melhorias no controle da corrupção. Dentre as diferentes iniciativas que são possíveis, uma se destaca devido à sua origem na sociedade civil: a proposta da lei da ficha limpa (RIBEIRO; PEREIRA; BENEDICTO, 2013, n.p.).

Fato é que tanto a Lei da Ficha Limpa quanto a Lei no 13.165/2015 (que altera consubstancialmente as exigências no processo eleitoral) contribuíram para que ocorressem mudanças no sistema político do país, mas não foram capazes ainda de extinguir a corrupção que se configura atualmente como uma chaga social.

Conforme Avritzer (2016), o país sofre com corrupção, a fraqueza das instituições, e os problemas na economia, havendo muito o que se fazer para mudar tal cenário. O Brasil já experimentou muitas crises no passado, mas, desta vez, está mais preparado para lidar com elas. 
As reformas da administração pública contribuíram para melhorar a capacidade de decisão política e para a descentralização do Estado, com a implementação da coordenação horizontal e modernização do potencial humano de gestão.

Potencializar saberes para conduzir um sistema político que de fato possa atender aos interesses da população se configura, hoje, num dos maiores desafios dos representantes públicos, pois, para se delinear um modelo desejado, é necessário reiniciar nas bases, e tal construção também precisa contar com a participação popular.

\section{Considerações finais}

Muito se fala da crise política brasileira. Várias "reformas" são realizadas sem que se consiga alcançar grandes reflexos na estrutura existente. Isto porque as mudanças apresentadas são sempre superficiais e as grandes alterações necessárias são deixadas num segundo plano, para um momento político mais propício.

É preciso romper algumas amarras criadas pela Constituição $\mathrm{Fe}$ deral de 1988 e fazer uma verdadeira reforma política (quiçá, até mesmo constitucional). O sistema político eleitoral existente já demonstrou seus sinais de esgotamento. A quantidade de partidos que há sem a apresentação de verdadeiras ideologias, até porque não haveria tantas ideologias assim, ao invés de contribuir para a democracia, acaba representando um retrocesso.

Já está provada a necessidade de mudança no sistema eleitoral. Mas, para isso, é preciso coragem para mudar. Coragem porque a elite política não quer jamais sofrer alterações em sua zona de conforto. $\mathrm{O}$ rompimento do atual modelo político resultaria no fim de alguns partidos e benefícios.

Porém, se não se desvincular dessas velhas amarras entre os poderes Legislativo e Executivo, com seus estreitos laços de articulações e acordos, o Brasil caminha para sua autodestruição política e democrática. 


\section{Referências}

ABRANCHES, Sérgio Henrique. Presidencialismo de coalizão: o dilema institucional brasileiro. Revista de Ciências Sociais, Rio de Janeiro, n. 31, p. 5-34, 1988.

ARAÚJO, Luiz Alberto David; NUNES JÚNIOR, Vidal Serrano. Curso de direito constitucional. 7. ed. São Paulo: Saraiva, 2003.

AVRITZER, Leonardo. A realidade política brasileira. 2016. Disponível em: <http://www.cartacapital.com.br/sociedade/a-realidade-politica-brasileira>. Acesso em: 27 ago. 2016.

CODATO, Adriano; COSTA, Luiz Domingos. O que é o presidencialismo de coalizão? 2006. Disponível em: <http://adrianocodato.blogspot.com. br/2006/12/o-que-o-presidencialismo-de-coalizo.html>. Acesso em: 17 jul. 2017.

CORDEIRO, Rodrigo Aiache. Sistemas partidários e sistemas eleitorais. In: Âmbito Jurídico, Rio Grande, XII, n. 65, jun 2009. Disponível em: < http:// www.ambito-juridico.com.br/site/index.php?n_link=revista_artigos_leitura\&artigo_id=6357>. Acesso em: 20 jul. 2017.

COSTA, Sylvio. O presidencialismo de coalizão. 2013. Disponível em: $<$ http://congressoemfoco.uol.com.br/noticias/o-presidencialismo-de-coalizao>. Acesso em: 2 jun. 2017.

CRESPO, Victor Hugo Marcão. Sistema partidário e o modelo brasileiro. In: Âmbito Jurídico, Rio Grande, XIII, n. 78, jul. 2010. Disponível em: $<$ http://www.ambito-juridico.com.br/site/index.php/\%3Fn_link\%3Drevista_artigos_leitura\%26artigo_id\%3D12427?n_link=revista_artigos_leitura\&artigo_id=7961\&revista_caderno=28>. Acesso em: 18 jul. 2017.

DANTAS, Rosalliny Pinheiro. Sistema presidencialista: origens, características e adoção pelo Brasil. 2011. Disponível em: <http://www.clubjus.com. br/?artigos\&ver=2.35865> . Acesso em: 26 ago. 2016.

GOMES, Luiz Flávio. O que se entende por princípios majoritário e proporcional? 2015. Disponível em: < http://lfg.jusbrasil.com.br/noticias/2542454/o-que-se-entende-por-principios-majoritario-e-proporcional $>$. Acesso em: 20 jun. 2017.

HAKIM, Peter. Política brasileira funciona há muito tempo no improviso. Carta Capital, 2016. Disponível em: < http://www.cartacapital.com. $\mathrm{br} /$ politica/politica-brasileira-funciona-ha-muito-tempo-no-improviso-3296. html>. Acesso em: 2 jul. 2017. 
LEITE, Antonio Teixeira. Os sistemas de governo. Revista Jus Navigandi, Teresina, ano 21, n. 4587, 22 jan. 2016. Disponível em: < https://jus.com.br/ artigos/45971>. Acesso em: 25 jul. 2017.

LIMONGI, Fernando. A democracia no Brasil: presidencialismo, coalizão partidária e processo decisório. Novos estud. - CEBRAP [online]. n. 76, p. 17-41, 2006a. ISSN 0101-3300. Disponível em: http://dx.doi.org/10.1590/ S0101-33002006000300002. Acesso em: 27 jul. 2017

. Presidencialismo, coalizão partidária e processo decisório. Novos Estudos, n. 76, nov. 2006b.

MORAES, Alexandre de. One man one vote: constituição do Brasil interpretada. São Paulo: Atlas, 2002.

MORAES, Filomeno. Executivo e Legislativo no Brasil pós-Constituinte. São Paulo Perspec. [online]. v. 15, n. 4, p. 45-52, 2001. ISSN 0102-8839. Disponível em: http://dx.doi.org/10.1590/S0102-88392001000400006. Acesso em: 27 jul. 2017

PIVA, Otávio. Presidencialismo sem coalizão: a ruptura do modelo de relacionamento entre poderes no governo Collor. Dissertação (Mestrado em Ciências Sociais) - Pontifícia Universidade Católica do Rio Grande do Sul, Porto Alegre, 2010.

REIS, Marisa Amaro dos. Multipartidarismo brasileiro: o excesso de partidos políticos e suas implicações. 2015. Disponível em: <https://jus.com.br/ artigos/38882/multipartidarismo-brasileiro-o-excesso-de-partidos-politicos-e-suas-implicacoes>. Acesso em: 17 jul. 2017.

RIBEIRO, Lívia Maria de Pádua; PEREIRA, José Roberto; BENEDICTO, Gideon Carvalho de. As reformas da administração pública brasileira: uma contextualização do seu cenário, dos entraves e das novas perspectivas. 2013. Disponível em: <http://200.144.182.143/escolausp/wp-content/uploads/2015/05/Reformas-administra>. Acesso em: 17 jul. 2017.

RICCI, Rudá. A coalizão presidencialista. Revista Espaço Acadêmico, n. 33, p. 2, 2008. Disponível em: <http://www.espacoacademico.com. br/083/83ricci02.htm>. Acesso em: 27 jul. 2017.

SANTOS, Fabiano. O poder legislativo no presidencialismo de coalizão. Belo Horizonte: Editora UFMG, 2003. 
SOARES, Marcos Antônio Striquer. Características do presidencialismo no Brasil e fragilidade democrática: dificuldades de controle do presidente da república no Brasil. Semina: Ciências Sociais e Humanas, Londrina, v. 24, p. 1-24, set. 2003.

SUPREMO TRIBUNAL FEDERAL. Eleição majoritária e proporcional. 2016. Disponível em: <http://www.brasil.gov.br/governo/2012/05/eleicao-majoritaria-e-proporcional>. Acesso em: 2 jul. 2017.

TORRES, Damiana. Sistemas eleitorais brasileiros. 2016. Disponível em: $<$ http://www.tse.jus.br/institucional/escola-judiciaria-eleitoral/revistas-da-eje/artigos/revista-eletronica-eje-n.-4-ano-4/sistemas-eleitorais-brasileiros>. Acesso em: 2 jul. 2017.

TRIBUNAL REGIONAL ELEITORAL DE SANTA CATARINA.

Entenda o funcionamento do sistema eleitoral proporcional. 2010. Disponível em: <http://tre-sc.jusbrasil.com.br/noticias/2411741/entenda-o-funcionamento-do-sistema-eleitoral-proporcional>. Acesso em: 27 ago. 2016.

VANIN, Carlos Eduardo. Sistema presidencialista. 2012. Disponível em: <http://www.jusbrasil.com.br/topicos/289833/sistema-presidencialista>. Acesso em: 25 jul. 2017.

VAZ, Anderson Rosa. Reestruturação do Poder Legislativo: Revista Jus Navigandi, Teresina, ano 5, n. 48, 1 dez. 2000. Disponível em: <https://jus. com.br/artigos/232>. Acesso em: 26 jul. 2017.

XEREZ, Alex Sanford Rangel. Breves considerações sobre o sistema eleitoral no Brasil. 2012. Disponível em: <http://www.direitonet.com.br/ artigos/exibir/7734/Breves-consideracoes-sobre-o-Sistema-Eleitoral-no-Brasil>. Acesso em: 20 jul. 2017.

Luiz Henrique Borges de Azevedo Silva - Técnico Judiciário do TRE/GO e professor do Instituto Aphonsiano de Ensino Superior. Mestre em Direito e Políticas Públicas pelo UNICEUB, especialista em Direito Penal (UFG), Direito Público (FESURV), Direito Constitucional (UFG) e Gestão Estratégica Educacional (FMB).

Nayra Juliana Daniel de Azevedo - Advogada e professora do Instituto Aphonsiano de Ensino Superior. Mestre em Desenvolvimento Regional pela ALFA, especialista em Direito Processual Penal e Civil (FESURV), Direito do Trabalho e Processo do Trabalho (Uni-Anhanguera) e Gestão Estratégica Educacional (FMB). 